\title{
CONCERNING CRANKS
}

\section{ROBERT J. BURDETTE}

What would we do were it not for cranks? How slowly the old world would move, did not cranks keep it rushing. Columbus was a crank, and at last he met the fate of most cranks-w-was thrown into prison and died in poverty and disgrace. Greatly venerated now? Oh, yes. Harvey was a crank on the subject of the circulation of the blood; Galilee was an astronomical crank; Fulton was a crank on the subject of steam navigation; Morse was a telegraph crank. All the old Abolitionists were cranks. The Pilgrim Fathers were cranks; John Bunyan was a crank; any man who doesn't think as you do, my son, is a crank. And by-and-by the crank you despise will have his name in every man's mouth, and a monument to his memory crumbling down in a dozen cities, while nobody outside of your native village will know that you ever lived. Deal gently with the crank, my boy. Of course, some cranks are crankier than others, but a crank is a thing that turns something, it makes the wheels go round, it insures progress. The thing that goes in for variety, that changes its position a hundred times a day, that is no crank; that is a weather-vane, my son. Maybe you couldn't be a crank, if you would. You thank Heaven you are not a crank, don't say that my son, Heaven is not very particular when it wants a weather-vane; almost any man will do for that. But when it wants a crank, my boy, it looks about very carefully. Before you thank Heaven that you are not a crank, examine yourself and see what it is that debars you from being a crank.

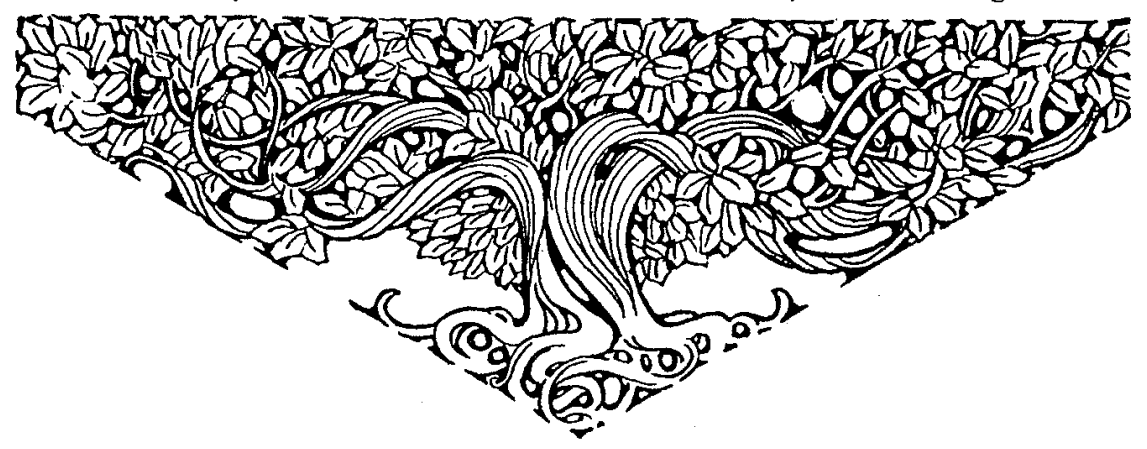

